\title{
SIGNATURE OF ADAPTIVE EVOLUTION AND FUNCTIONAL DIVERGENCE OF TLR SIGNALING PATHWAY GENES IN TIBETAN NAKED CARP GYMNOCYPRIS PRZEWALSKII
}

\author{
Chao Tong ${ }^{1,2}$, Kai Zhao ${ }^{1, *}$ \\ ${ }^{1}$ Key Laboratory of Adaptation and Evolution of Plateau Biota, Northwest Institute of \\ Plateau Biology, Chinese Academy of Sciences, Xining, 810001, China \\ ${ }^{2}$ University of Chinese Academy of Sciences, Beijing, 100049, China
}

\begin{abstract}
The Tibetan naked carp Gymnocypris przewalskii is a newly diverged species from Schizothoracinae fish, only dwelled in the China largest salt lake, Qinghai Lake. Its living condition is hypoxia, cold temperature and high salinity. Noteworthy, it is more susceptible to parasite infection in freshwater that wild environment. Our recent genome wide analyses studies indicated that naked carp TLR signaling pathway genes, TLR4 and TLR9 within TLR family, IRF3, IRF5 and IRF7 within IRF family underwent significant positive selection in response to the inhospitable environment trigged by the uplift of the Tibetan Plateau. The experimental evidences indicate that TLR4 gene function towards neofunctionalization when exposure to parasite infection, IRF3 and IRF4 towards significant functional divergence in biotic and abiotic stress response. These finding provide novel insights into evolutionary history and molecular mechanism of highland fish respond to environment changes.
\end{abstract}

\section{KEYWORDS:}

Positive selection, Functional divergence, TLRs, IRFs, Tibetan fish

First author's information:

E-mail: tongchao_2009@sina.com; tongchao1990@gmail.com

*Corresponding author.

E-mail: zhaokai@nwipb.ac.cn 